Research Article

\title{
Numerical Simulation of the Tar Mist and Dust Movement Process in a Low-Temperature Dry Distillation Furnace
}

\author{
Qiuli Zhang $\mathbb{D}^{1},{ }^{1}$ Xiangrong Hui $\mathbb{D}^{1},{ }^{1}$ Long Yan, ${ }^{2}$ Min Luo $\mathbb{D},{ }^{1}$ Wenru Feng, ${ }^{1}$ Jun Zhou, \\ and Xinzhe Lan $^{3}$ \\ ${ }^{1}$ School of Chemistry and Chemical Engineering, Xi'an University of Architecture and Technology, Xi'an 710055, Shaanxi, China \\ ${ }^{2}$ College of Chemistry and Chemical Engineering, Yulin University, Yulin 719000, Shaanxi, China \\ ${ }^{3}$ Research Centre on Metallurgical Engineering and Technology of Shaanxi Province, Xi'an 710055, Shaanxi, China
}

Correspondence should be addressed to Qiuli Zhang; qiulizhang@126.com

Received 28 November 2019; Revised 30 December 2019; Accepted 3 January 2020; Published 2 March 2020

Academic Editor: Marco Anni

Copyright (c) 2020 Qiuli Zhang et al. This is an open access article distributed under the Creative Commons Attribution License, which permits unrestricted use, distribution, and reproduction in any medium, provided the original work is properly cited.

In the low-temperature dry distillation of low-rank coal, the important liquid product of coal tar is produced, but its quality and utilization rate are degraded by entrained dust. The movement of coal tar and dust in the furnace is a key factor in causing particles such as dust to mix with coal tar. Therefore, the Euler-Lagrangian method is used to simulate the two-phase motion process of gas, tar, and dust in a furnace. By considering the effects of tar particle size, dust particle size, gas velocity, tar density, and dust density, the motion process mechanism is revealed, enabling the dust content in coal tar to be reduced and the quality improved. The results indicate that tar particles with sizes less than $0.20 \mathrm{~mm}$ can be removed from the furnace by gas, and the smaller the particle size is, the shorter the time required for removal. Dust particles greater than $0.18 \mathrm{~mm}$ in size cannot be completely removed from the furnace. As the gas velocity increases, the time required for complete removal of the tar mist and dust gradually decreases. When the speed is $0.70 \mathrm{~m} / \mathrm{s}$, all tar mist is removed, although some particles remain. Tar mist with a density of more than $900 \mathrm{~kg} / \mathrm{m}^{3}$ can be extensively removed, but dust with a density of more than $1400 \mathrm{~kg} / \mathrm{m}^{3}$ is difficult to remove and remains in the furnace. Finally, particle size distribution experiments in the product were conducted to verify the accuracy of the numerical simulation.

\section{Introduction}

China's coal resources are relatively abundant, and its reserves account for approximately $90 \%$ of the country's mineral resource reserves and $95 \%$ of its fossil energy, with significant resource potential [1]. Moreover, the country's coal resources include coal types from lignite to anthracite in various coalification stages, especially low-rank reserves that account for more than $40 \%$ of coal reserves and occupy a vital position in China's coal resources [2,3]. Coal accounts for approximately $72 \%$ of the country's total energy consumption, and China's coal-based energy structure is expected to remain stable for a long time [4].

China's northern Shaanxi region is rich in coal resources, with proven reserves of 146 billion tons. These resources are dominated by low-rank long-flame coal, which has a high oil content (average 6\% to 7\%) and has the characteristics of "three lows and one high" (low ash, low sulfur, low phosphorus, and high calorific value). This coal is an ideal raw material for low-temperature retorting [5]. Coal dry distillation is a necessary process for coal conversion processes such as coal liquefaction [6], gasification [7], combustion, and coking [8]. In addition, coal dry distillation is an efficient, low-pollution coal classification and conversion technology [9-11]; the gas produced during the dry distillation process can be used as a fuel and industrial raw material [12], and semicoke can be used in the metallurgical industry, syngas production, and other fields [13]. The phenols and hydrocarbons rich in coal tar become important raw chemical materials after separation and purification [14]; moreover, this material can partially replace oil and optimize the energy allocation of the petrochemical industry. China's crude oil storage is small, and China has long relied on imports. Therefore, improving the production and 
quality of coal tar during low-temperature dry distillation can partially alleviate China's petroleum energy crisis and substantially augment China's reserve oil.

In the low-temperature dry distillation process, the furnace type adopted in the northern part of Shaanxi is mainly an SJ-type internal heat low-temperature dry distillation furnace. This furnace type is a new process developed by a company based on the Lurgi-Spilgas threestage furnace. It utilizes the advantages of related furnace types at home and abroad, combines local actual production experience, and designs according to the characteristics of low-rank coal. A moving bed reactor is used, and the burned gas is used as a gas heat carrier to heat coal in the bed to facilitate the pyrolysis reactions of the coal. The process is simple, and a high yield of tar can be obtained, making this process one of the preferred techniques for low-rank coal cryogenic dry distillation in China. However, the furnace gas produced by the process is cooled during the temperature rise, and part of the tar forms liquid tar mist. Moreover, dust such as pulverized coal and semicoke entrained in the furnace gas flow are also incorporated, which makes the separation and recovery of coal tar difficult, resulting in poor quality and greatly reducing the potential value of the tar. Therefore, the separation of coal tar and impurities has become a key problem. Based on actual observations of phase flow and the complexity of measuring industrial data, it is very difficult to solve this problem by experimental methods. However, with the rapid development of computers, the computational fluid dynamics (CFD) method has gradually become effective for studying complex multiphase flow processes in reactors. Many researchers have implemented the coupling of complex reaction kinetic models into CFD models for flowphase simulation [15-18]. This work provides a technical basis for the simulation calculation of tar mist and dust movement processes by the CFD method.

Currently, the calculation methods of fluid-solid coupling are divided into three categories: the Euler-Eulerian method, the Euler-Lagrangian method, and the LagrangianLagrangian method. Because the Euler-Lagrangian method can accurately reflect the airflow-dust coupling characteristics [19-22], this method is increasingly widely used in the simulation of fluid-solid two-phase flow. Torañod et al. [23] studied the migration behavior of airflow and air-dust flow through a $14.7-\mathrm{m}^{2}$ cross section on a fully mechanized excavation surface under strong exhaust ventilation conditions by the Euler-Lagrangian method. Kurnia et al. [24] used the Euler-Lagrangian method to study the diffusion and management of dust on the excavation surface. Patankar and Joseph [25] used the Lagrangian method to describe the movement of dust particles.

In previous studies, numerical simulations have been widely used to study the dust diffusion pollution behavior in coal, and some useful results have been achieved. For example, $\mathrm{Lu}$ et al. [26] used CFD to evaluate various possible scenarios for underground mine configurations. Zhou et al. [27] combined CFD simulation and onsite measurement to study the diffusion behavior of inhalable dust. Cai et al. [28] studied the effect of airflow on the diffusion mode of coal dust particles in a fully mechanized mining face and found the optimal airflow.

In the past 5 years, the model of pulverized coal-fired boilers has improved significantly. Modeling furnaces for coal-fired boilers is a complex task. Any model developed to predict critical performance parameters, such as furnace exit gas temperature and pollutant emission levels, will need to capture the multifarious nature of combustion in the boiler furnace. Despite the large amount of computationally expensive CFD codes, researchers have also developed simpler but effective reactor network models. Sankar et al. [29] reviewed the research status of calculation models for pulverized coal boilers from three perspectives: the development of coal combustion models, radiation models, and overall furnace models.

Nevertheless, there are very few simulation studies on the movement process of focusing tar oil mist and dust in a low-temperature dry distillation furnace. Through numerical simulation of the gas-solid two-phase flow state, the twophase motion mechanism of the coal retorting process is revealed. The physical parameters (e.g., particle size of tar and dust, gas velocity, and density of tar and dust) can be optimized so that the tar can be quickly removed by the gas, while the dust, such as pulverized coal and semicoke, remains in the furnace to continue pyrolysis. This condition can reduce the waste slag in the coal tar, improve the quality of the coal tar, partially alleviate China's petroleum energy crisis, and substantially augment China's reserve oil. In addition, the raw materials can be brought closer to the theoretically superior value before production, thereby improving the efficiency of pyrolysis production and reducing energy consumption and costs.

\section{Physically Simplified Model of Airflow- Particle Motion}

In an SJ-type internal heat type low-temperature dry distillation furnace, the tar that is dry distillated by coal exists in a gaseous form in the high-temperature region. The tar and gas move upward in the space between the coal particles, and when it reaches the low-temperature region (below the boiling temperature of the tar component), the tar condenses into a tar mist. The main components and boiling points of tar are shown in Table 1.

The tar mist is brought out of the furnace by the rapidly rising gas. At the same time, the coal generates dust when it enters the furnace, and some of this dust is removed from the furnace by the gas. By simplifying the model, the process of tar mist and dust removal by gas is considered a pneumatic conveying process. Showing a characteristic length of $L$ (unit is $\mathrm{m}$ ) and an equivalent diameter of $d$ (unit is $\mathrm{m}$ ) of the microelement tube as the research object, a schematic diagram of the tar mist and dust movement is shown in Figure 1, where $u$ is the apparent velocity in $\mathrm{m} / \mathrm{s}$ and $n$ is the void fraction. Due to the presence of scattered solid particles in the tube, which increases the difficulty of establishing the geometric model, we arrange the scattered solid particles in Figure 1(a) in an orderly manner to obtain Figure 1(b). When the arrangement is tight enough, we can ignore its 
TABLE 1: Main components and boiling points of tar.

\begin{tabular}{|c|c|c|}
\hline Main components & & Boiling points $\left({ }^{\circ} \mathrm{C}\right)$ \\
\hline Alkanes & $\begin{array}{c}\mathrm{C}_{11}-\mathrm{C}_{19} \\
\mathrm{C}_{\geq 20}\end{array}$ & $\begin{array}{c}195.8-330.0 \\
\geq 343.0\end{array}$ \\
\hline \multirow{2}{*}{ Phenols } & Phenol & 181.9 \\
\hline & Naphthol & 285.3 \\
\hline \multirow{5}{*}{ Aromatic hydrocarbons } & Benzene & 80.1 \\
\hline & Toluene & 110.6 \\
\hline & Dimethyl-benzene & $139.1 / 138.4$ \\
\hline & Naphthalene & 217.9 \\
\hline & Anthracene & 340.0 \\
\hline \multirow{2}{*}{ Nitrogen-containing compound } & Pyridine & 115.2 \\
\hline & Quinoline & 238.1 \\
\hline
\end{tabular}

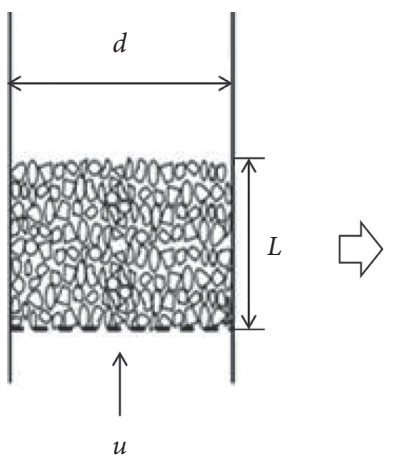

(a)

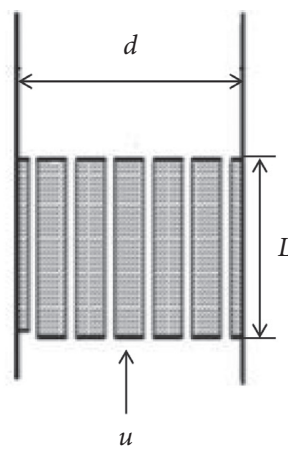

(b)

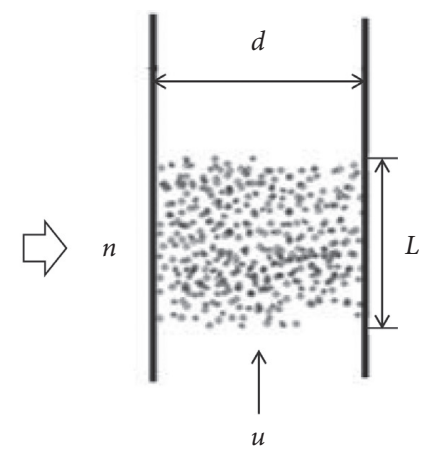

(c)

FIgURE 1: Schematic diagram of the tar mist and dust movement.

existence in the tube and then express it by a void fraction. The movement process of tar mist and dust in the tube is shown in Figure 1(c).

\section{Mathematical Model of Airflow- Particle Motion}

In this study, gas is considered as the fluid phase, and tar mist and dust are considered as the particle phase. It is also assumed that the flow of gas in the model conforms to the continuous medium hypothesis, conservation of energy law, and Newton's second law of motion [30]. On the basis of the standard $k-\varepsilon$ model, we constructed the closed control equations to calculate the turbulence. This model only considered momentum transfer and ignored thermal conduction. Then, dust particles were treated as discrete media whose movements were calculated based on the Lagrangian method $[27,31,32]$. The associated mathematical models are as follows.

3.1. Mathematical Model of Air Movement. The continuity equation $[33,34]$ :

$$
\frac{\partial \rho}{\partial t}+\frac{\partial}{\partial x_{i}}\left(\rho u_{i}\right)=0 .
$$

The Navier-Stokes equation: $\frac{\partial}{\partial t}\left(\rho u_{i}\right)+\frac{\partial}{\partial x_{i}}\left(\rho u_{i} u_{j}\right)=-\frac{\partial p}{\partial x_{i}}+\frac{\partial}{\partial x_{j}}\left[\left(\mu+\mu_{t}\right)\left(\frac{\partial u_{i}}{\partial x_{j}}+\frac{\partial u_{j}}{\partial x_{i}}\right)\right]$

where $\rho$ is the fluid density; $t$ is time; $x$ is the coordinate; $u$ is velocity; $p$ is the turbulent pressure; and $\mu_{t}$ is the coefficient of turbulent viscosity.

The energy equation [35]:

$$
\frac{\partial}{\partial t}(\rho h)+\frac{\partial}{\partial x_{i}}\left(\rho u_{i} h\right)=\frac{\partial}{\partial x_{j}}\left(\Gamma_{h} \frac{\partial h}{\partial x_{j}}\right)+\frac{\partial p}{\partial t}+\frac{\partial u_{i} p}{\partial x_{i}}+\Phi+S^{h},
$$

where $h$ is the specific enthalpy, $\Gamma_{h}$ is the ratio of effective viscosity and the Prandtl number, $\Phi$ is the dissipation function, and $S^{h}$ is the source of enthalpy generated on a volumetric source basis. $\Phi$ can further be calculated as

$$
\Phi=\mu\left[\frac{\partial u_{i}}{\partial x_{j}}+\frac{\partial u_{j}}{\partial x_{i}}-\delta_{i j} \frac{2}{3}\left(\frac{\partial u_{k}}{\partial x_{k}}\right)\right] \frac{\partial u_{i}}{\partial x_{j}} .
$$

Standard $k-\varepsilon$ equation:

The $k$-equation [36, 37]:

$\frac{\partial(\rho k)}{\partial t}+\frac{\partial\left(\rho k u_{i}\right)}{\partial x_{i}}=\frac{\partial}{\partial x_{i}}\left[\left[\mu+\frac{\mu_{t}}{\sigma_{k}}\right] \frac{\partial k}{\partial x_{i}}\right]+G_{k}-\rho \varepsilon$.

The $\varepsilon$-equation: 


$$
\frac{\partial(\rho \varepsilon)}{\partial t}+\frac{\partial\left(\rho \varepsilon u_{i}\right)}{\partial x_{i}}=\frac{\partial}{\partial x_{j}}\left[\left[\mu+\frac{\mu_{t}}{\sigma_{\varepsilon}}\right] \frac{\partial \varepsilon}{\partial x_{j}}\right]+\frac{C_{1 \varepsilon^{\varepsilon}}}{k} G_{k}-C_{2 \varepsilon} \rho \frac{\varepsilon^{2}}{k} .
$$

In these equations, $k$ is the fluid's turbulent kinetic energy; $\varepsilon$ is the viscous dissipation induced by a vortex; $G_{k}$ is the turbulent kinetic energy; and $C_{1 \varepsilon}, C_{2 \varepsilon}$, and $C_{\mu}$ are the empirical constants with values of $1.44,1.92$, and 0.09 , respectively.

3.2. Force Analysis of the Fluid Phase. As shown in Figure 1, in the microelement length $L$, the intracavity void ratio is $n$, and it is assumed that the in-tube free cross section fraction is equal to $n$.

The fluid phase is subjected to a frictional resistance $F_{f, g}$, the force of the pressure drop gradient on the fluid phase $F_{\Delta p}$, $g$, the self-gravity, and the particle $\operatorname{drag} F_{D, g}$. All other forces are negligible:

$$
\begin{aligned}
F_{f, g} & =\Delta p_{f} \frac{n \pi d^{2}}{4} \\
F_{\Delta p, g} & =-\frac{\partial p}{\partial z} \frac{n \pi d^{2} \Delta L}{4} \\
F_{D, g} & =-\frac{18 \mu}{\rho_{g} d^{2}} \frac{C_{D} \operatorname{Re}}{24}
\end{aligned}
$$

where $\Delta p_{f}$ is the pressure difference generated by the fluid motion, and the unit is $\mathrm{Pa}$.

\subsection{Mathematical Model of Tar Mist and Dust Movement.} In the Lagrangian coordinate system, the motion trajectory of discrete-phase particles was calculated by integrating the differential equation of the interaction among particles [30, 38-40].

Time-averaged particle velocity $\vec{u}_{p}$ is calculated as the sum of particle convective velocity $\vec{u}_{p c}$ and diffusive velocity $\vec{u}_{p d}$ [41]. The convective velocity of particles is

$m_{p} \frac{\mathrm{d} \vec{u}_{p c}}{\mathrm{~d} t}=C_{D} \rho \frac{A_{p}}{2}\left(\vec{u}-\vec{u}_{p c}\right)\left|\vec{u}-\vec{u}_{p c}\right|+\frac{d_{p}^{3} \pi}{6}\left(\rho_{p}-\rho\right) \vec{g}$.

The diffusive velocity:

$$
\vec{u}_{p d}=-\frac{1}{N_{p}} \Gamma_{p} \nabla N_{p}
$$

The additional forces in the particle force balance, mainly including the pressure gradient force, virtual mass force, Saffman lift force, and Magnus lift force, are important under special circumstances [42].

The pressure gradient force:

$$
\vec{F}_{p}=\frac{\rho}{\rho_{p}} \vec{u}_{p} \nabla \vec{u}
$$

The virtual mass force:

$$
\vec{F}_{v m}=C_{v m} \frac{\rho}{\rho_{p}}\left[\vec{u}_{p} \nabla \vec{u}-\frac{\mathrm{d} \vec{u}_{p}}{\mathrm{~d} t}\right],
$$

where $C_{v m}$ is the virtual mass factor with a fixed value of 0.5 .

The Saffman lift force $[43,44]$ :

$$
\vec{F}_{S a f}=\frac{2 K v^{1 / 2} \rho d_{i j}}{\rho_{p} d_{p}\left(d_{l k} d_{k l}\right)^{1 / 4}}\left(\vec{u}-\vec{u}_{p}\right)
$$

where $K=2.594 ; d_{i j}, d_{l k}$, and $d_{k l}$ refer to the deformation tensor; and $v$ is the kinematic viscosity.

The Magnus lift force:

$$
\vec{F}_{\mathrm{Mag}}=\frac{\pi d_{p}^{3} \rho \vec{\omega}\left(\vec{u}-\vec{u}_{p}\right)}{2},
$$

where $\vec{\omega}$ is the rotational angular velocity.

\section{Geometry Model Establishment and Boundary Condition Setting}

Figure 2 is a schematic diagram of the structure of a 75,000ton SJ-type internal heat low-temperature dry distillation furnace used by a coal chemical company in Shaanxi. The furnace adopts a cavity design. From top to bottom is a drying section, a dry distillation section, and a cooling section. Coal blocks gradually descend from the coal box through the cavity. The gas and air are mixed into the furnace from below, and the gas and oxygen burn to form a high-temperature heat carrier to heat the coal seam layer by layer. The tar produced by pyrolysis is removed from the riser by rising gas. According to this process, a geometrical model of the riser is constructed, which is divided into a square grid with a total of 15,320 cells, including 40 cells on the $X$-axis and 383 cells on the $Y$-axis. As shown in Figure 3, the mesh with quality higher than 0.3 accounts for more than $97 \%$ of all meshes, indicating that the mesh model is reasonable.

In practice, it is a continuous process for tar mist and dust to be removed from the furnace by the rising gas, but it is difficult to simulate this process. Therefore, in the numerical simulation, it is assumed that the lower part of the riser is filled with particles with a volume fraction of $30 \%$, and the gas is then blown upward from the bottom of the tube at a certain speed to observe the rise of particles. Figure 4 shows the state of the particles in the tube filling the bottom (red portion) before iteration after setting the particle volume fraction to $30 \%$ in ANSYS Fluent.

Because the tar mist particles only exist in the riser, once they are removed from the furnace, they will agglomerate to form liquid tar. It is difficult to directly measure during the production process, so a large number of simulation experiments were performed in the early stage to determine the particle size scope. Finally, the research scope is determined as follows: the tar mist particle size is $0.1 \mathrm{~mm}-1.0 \mathrm{~mm}$, and the dust particle size is $0.05 \mathrm{~mm}-0.20 \mathrm{~mm}$. According to the density scope of tar and dust provided by the coal chemical company, numerous simulation experiments were carried out in the early stage. The final determination scope is as 


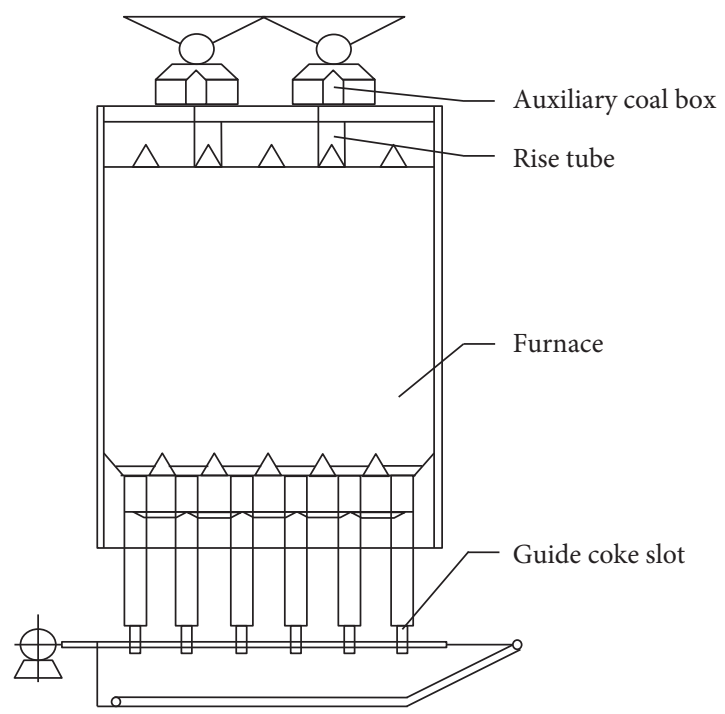

FIGURE 2: Schematic diagram of the structure of SJ-type internal heat low-temperature dry distillation furnace.

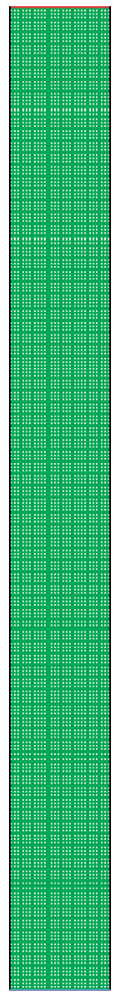

Figure 3: Geometric model of the riser.

follows: tar mist density $900 \mathrm{~kg} / \mathrm{m}^{3}-1100 \mathrm{~kg} / \mathrm{m}^{3}$ and dust density $1100 \mathrm{~kg} / \mathrm{m}^{3}-1500 \mathrm{~kg} / \mathrm{m}^{3}$. The scope of gas velocity provided by the coal chemical company is $0.675-0.723 \mathrm{~m} / \mathrm{s}$. In this study, $0.68,0.69,0.70,0.71$, and $0.72 \mathrm{~m} / \mathrm{s}$ were selected as the gas velocities. Table 2 lists the boundary conditions for the geometric model.

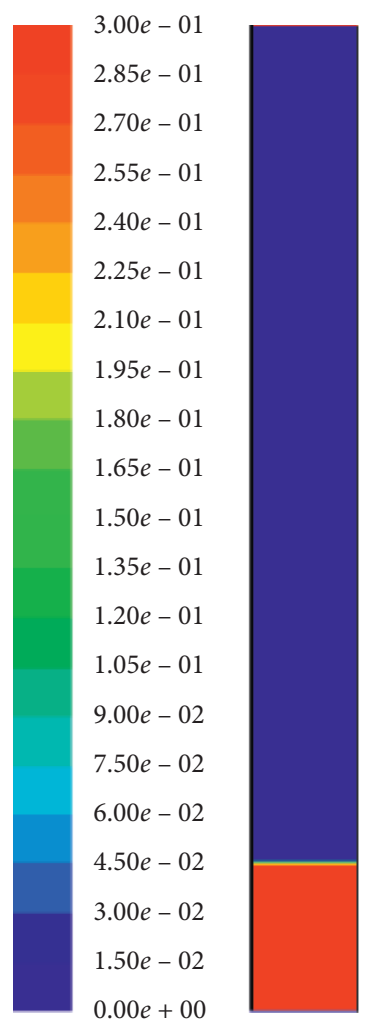

FIgURE 4: Initial state particle volume fraction.

\section{Results and Discussion}

5.1. Effect of the Tar Mist Particle Size. When the gas velocity is $0.70 \mathrm{~m} / \mathrm{s}$ and the density of the tar mist is $900 \mathrm{~kg} / \mathrm{m}^{3}$, the particle size of the tar mist is changed to study the two-phase motion. Figure 5 shows the volume fraction of the tar mist at different times.

It can be seen from Figures 5(a) and 5(b) that the distribution area of the particles in the furnace increases rapidly with time, and the entire area is filled within $1.8 \mathrm{~s}$. Then, the distribution of the particles in the working area is continuously reduced until the particles are completely removed by the gas. When the particle size is $0.10 \mathrm{~mm}$ and the time is $6.1 \mathrm{~s}$, only particles at a volume fraction of 0.03 are present in the furnace, and the remaining positions are filled with the gas phase, indicating that $97 \%$ of the tar particles are carried out by the gas. When the particle size is $0.20 \mathrm{~mm}$ and the time is $0.9 \mathrm{~s}$, the particles are brought to a height of approximately $4 / 6$ in the tube; when the time reaches $22.0 \mathrm{~s}$, the particles are all carried out of the working area by the gas.

It can be seen from Figures 5(c) and 5(d) that within $1.8 \mathrm{~s}$, the particle distribution area begins to decrease significantly; from $1.8 \mathrm{~s}$ to $120 \mathrm{~s}, 95 \%$ of the particles are below a height of $1 / 2$, and the distribution area and state are similar. After $120 \mathrm{~s}$, this state remains unchanged, indicating that the particles are difficult to remove. In Figure 5(e), the particle distribution area is always at a height of $1 / 6$, and the area does not change very much with time, indicating that the particles are also hard to remove in this case. 
TABLE 2: Boundary conditions of the geometric model.

\begin{tabular}{lccc}
\hline Name & Parameter & Name & Parameter \\
\hline Solver & Discrete solver & Inlet boundary type & Velocity_Inlet \\
Turbulence model & $k-\varepsilon$ two-equation & Turbulence intensity & $3.2 \%$ \\
Energy equation & Close & Outlet boundary type & Outflow \\
Discrete-phase model & Open & Convergence criterion & $10^{-3}$ \\
Drag law & Spherical & Particle size distribution & Rosin-Rammler \\
Drag coefficient & Syamlal-O’Brien & Shear condition & No slip \\
Pressure interpolation method & Standard format & Pressure-velocity coupling equation & SIMPLEC \\
\hline
\end{tabular}

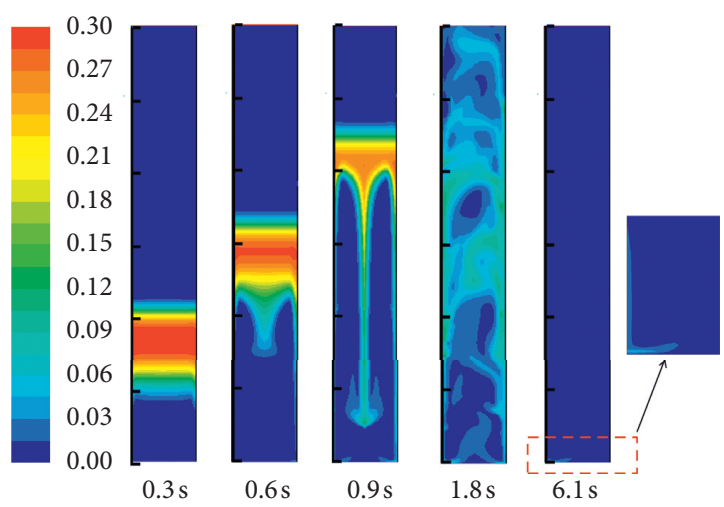

(a)

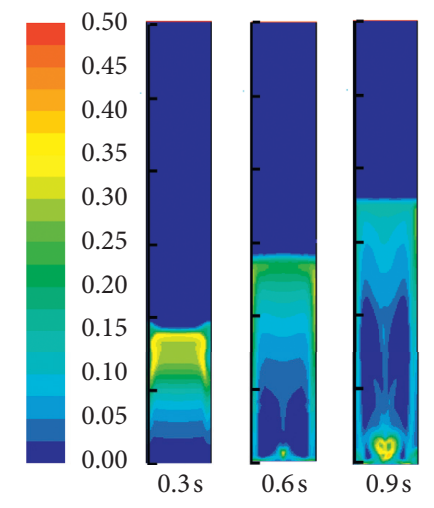

(c)
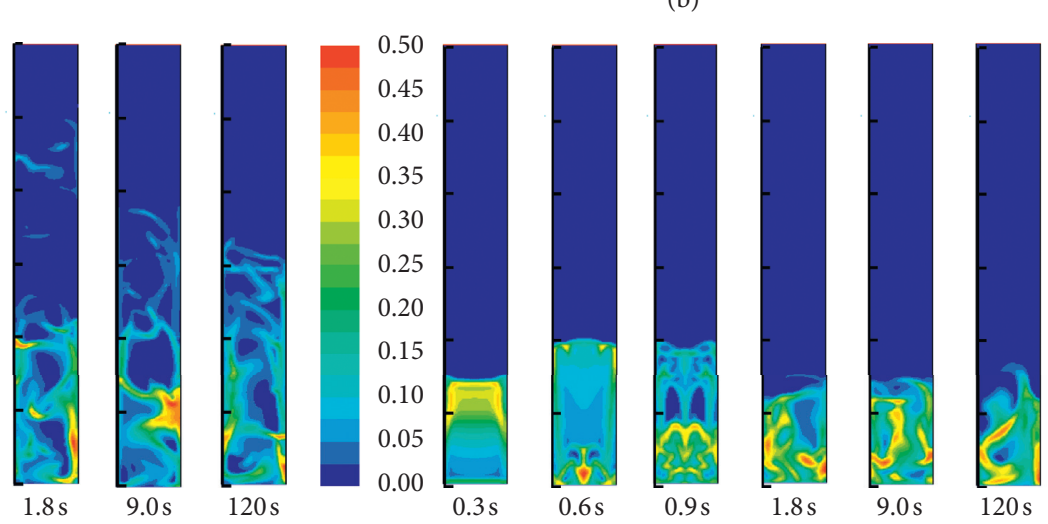

(d)

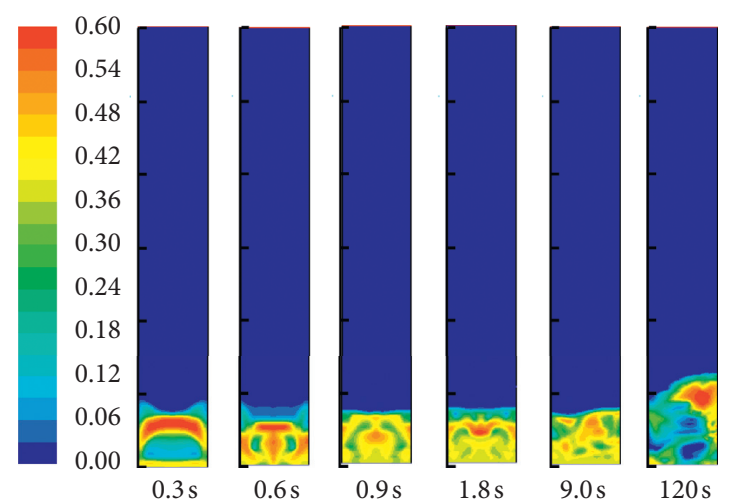

(e)

Figure 5: Volume fraction of tar mist: $u=0.70 \mathrm{~m} / \mathrm{s}$ and $\rho=900 \mathrm{~kg} / \mathrm{m}^{3}$. (a) $d=0.10 \mathrm{~mm}$. (b) $d=0.20 \mathrm{~mm}$. (c) $d=0.30 \mathrm{~mm}$. (d) $d=0.50 \mathrm{~mm}$. (e) $d=1.00 \mathrm{~mm}$. 

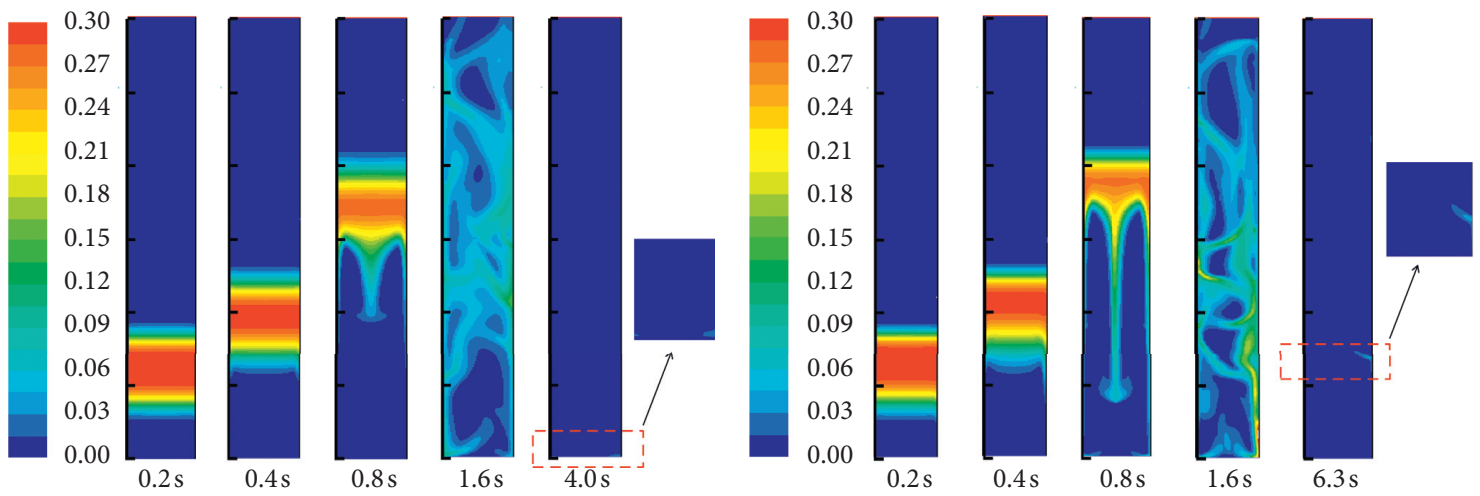

(a)
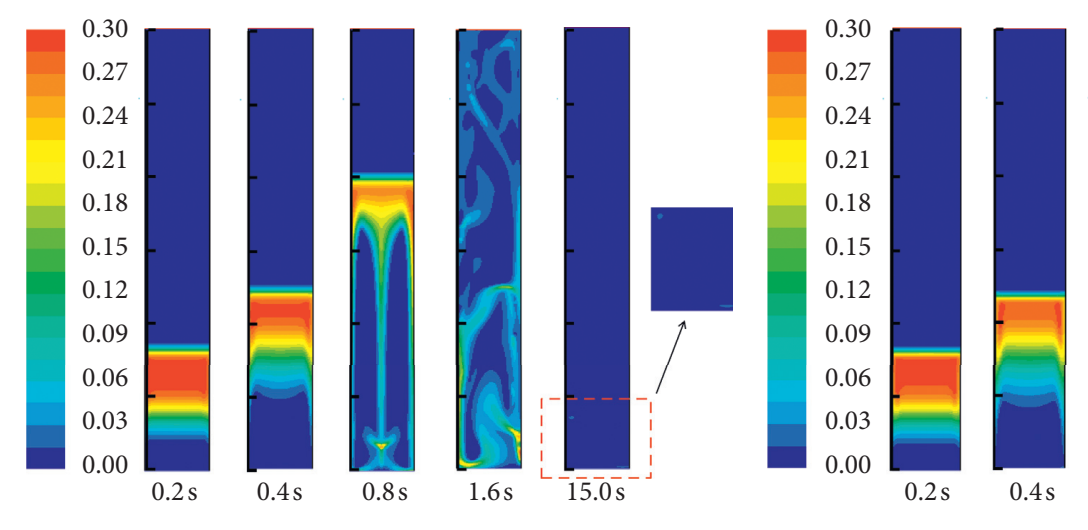

(b)

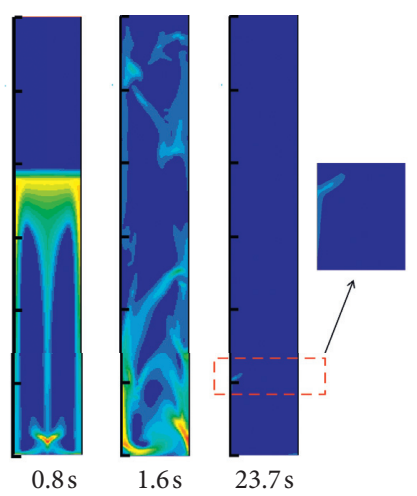

(c)

(d)
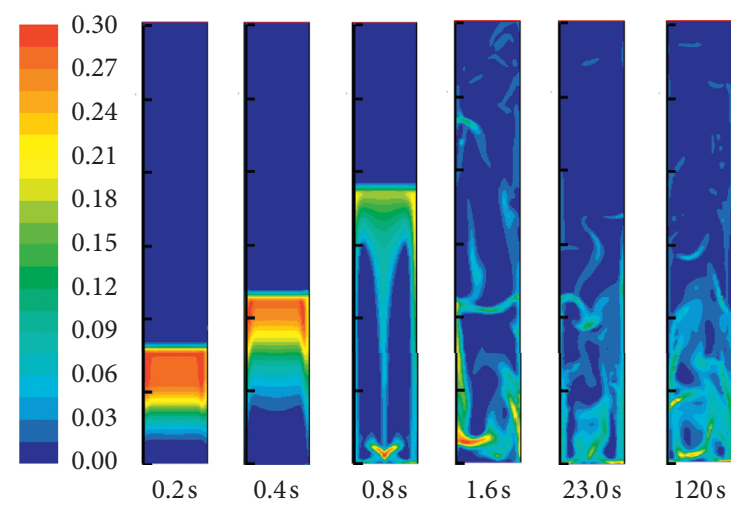

(e)

Figure 6: Volume fraction of dust: $u=0.70 \mathrm{~m} / \mathrm{s}$ and $\rho=1100 \mathrm{~kg} / \mathrm{m}^{3}$. (a) $d=0.05 \mathrm{~mm}$. (b) $d=0.10 \mathrm{~mm}$. (c) $d=0.15 \mathrm{~mm}$. (d) $d=0.18 \mathrm{~mm}$. (e) $d=0.20 \mathrm{~mm}$.

A comparison of Figures 5(c)-5(e) indicates that the volume fraction of the particles at the bottom of the furnace is unevenly distributed, and the particles are fluidized. Moreover, as the particle size increases, the particle distribution area gradually decreases, as does the degree of fluidization of the particles. A comparison of the subfigures of Figure 5 reveals that as the particle size increases, the distribution area of the particles decreases at every time point, the volume at the bottom gradually increases, and the degree of fluidization gradually decreases. At the same gas velocity, the larger the particle size, the more difficult removal becomes.
5.2. Effect of the Dust Particle Size. When the gas velocity is $0.70 \mathrm{~m} / \mathrm{s}$ and the dust density is $1100 \mathrm{~kg} / \mathrm{m}^{3}$, the particle size of the dust is changed to study the two-phase motion. Figure 6 shows the volume fraction of dust at different times.

Figures 6(a)-6(d) show that the distribution area of the particles in the furnace increases rapidly with time, and the entire area is filled within $1.6 \mathrm{~s}$. Then, the distribution of the particles in the working area is continuously reduced. Finally, only particles at a volume fraction of 0.015 remain, the rest having been removed by the gas. As the particle size of the dust increases, the time required for dust removal gradually increases. In Figure 6(e), when the particle size of 
the dust is $0.20 \mathrm{~mm}$, the distribution area and the volume fraction at 23.0 and $120 \mathrm{~s}$ do not change much, and the particles are deemed difficult to remove.

In Figure 6, the particle distributions of $0.2 \mathrm{~s}$ and $0.4 \mathrm{~s}$ are the same, and only the proportions of the different volume fractions are different. Particles (with a volume fraction of 0.30 ) are gradually depleted, and the proportion of remaining particles gradually increases, producing a volume fraction between 0.27 and 0.03 . At $0.8 \mathrm{~s}$, the distribution of the upper part is unchanged, but the volume fraction is gradually reduced, the height of the particles is slightly lowered, and the volume fraction at the bottom is gradually increased. These effects are caused by the increase in particle size. At $1.6 \mathrm{~s}$, the particles fill the entire working area; however, as the particle size increases, the upper distribution area decreases, and particles gradually gather at the bottom with a volume fraction of 0.30 .

5.3. Experimental Verification. The above simulation results demonstrate that the influence of the particle size on the rise of oil mist and dust is important. Zhang et al. [42] used the AKFC-92A-type mine dust sampler to perform dust sampling 30 minutes after coal mining to verify the accuracy of the simulation results. To verify the accuracy of the simulation results, Cai et al. [28] set up multiple measurement points onsite and collected dust particle samples using a dust sampler to measure the dust concentration. However, due to the complicated structure of the coal low-temperature dry distillation furnace and the uninterrupted production process, it is difficult for the measuring instrument to be directly introduced into the rising pipe for measurement. The coal tar produced on-site by this type of a low-temperature dry distillation furnace in a factory is dissolved with an organic solvent such as toluene, acetone, or quinoline, followed by suction filtration and washing to obtain dust particles, and the particle size distribution of the dust is measured by the OMEC Topsizer Plus laser particle size analyzer. The obtained particle size distribution is shown in Table 3 and Figure 7.

As shown in Figure 7, the dust particles less than $0.18 \mathrm{~mm}$ accounted for $90 \%$, and the largest particle size was not more than $0.339 \mathrm{~mm}$, indicating that the dust particles less than $0.18 \mathrm{~mm}$ were easily taken out by the gas and affected the quality of the tar. It can be seen from Figure 6(e) that the $0.20 \mathrm{~mm}$ dust cannot be completely taken out, but it is not solidified like tar mist deposited on the bottom, or a small part will be taken out, which accounts for about $4.68 \%$ (Table 3). In summary, it was found that the particle size distribution could achieve the expected simulation effect in practice. By comparing the particle size change in experiments and simulations, the effects on the dust rising process were investigated, and the accuracy of the mathematical models used in the simulation process and the reliability of the simulation results were verified. The rationality of particle size parameter selection was further proven.

5.4. Effect of the Gas Velocity on the Tar Mist and Dust Movement. Two-phase motion is studied by changing gas velocity. The volume fractions of tar mist and dust are shown in Figures 8 and 9, respectively.
TABle 3: Dust particle size frequency and cumulative distribution.

\begin{tabular}{|c|c|c|}
\hline Dust particle size $(\mathrm{mm})$ & $\begin{array}{c}\text { Frequency } \\
\text { distribution (\%) }\end{array}$ & $\begin{array}{c}\text { Cumulative } \\
\text { distribution (\%) }\end{array}$ \\
\hline 0.0020 & 0.00 & 0.00 \\
\hline 0.0024 & 0.16 & 0.16 \\
\hline 0.0028 & 0.05 & 0.22 \\
\hline 0.0033 & 0.07 & 0.29 \\
\hline 0.0039 & 0.09 & 0.38 \\
\hline 0.0046 & 0.12 & 0.51 \\
\hline 0.0055 & 0.16 & 0.67 \\
\hline 0.0065 & 0.22 & 0.89 \\
\hline 0.0077 & 0.29 & 1.17 \\
\hline 0.0091 & 0.38 & 1.55 \\
\hline 0.0108 & 0.50 & 2.05 \\
\hline 0.0128 & 0.66 & 2.70 \\
\hline 0.0151 & 0.86 & 3.57 \\
\hline 0.0179 & 1.13 & 4.70 \\
\hline 0.0212 & 1.48 & 6.18 \\
\hline 0.0250 & 1.92 & 8.10 \\
\hline 0.0296 & 2.49 & 10.58 \\
\hline 0.0351 & 3.19 & 13.77 \\
\hline 0.0415 & 4.05 & 17.82 \\
\hline 0.0491 & 5.07 & 22.89 \\
\hline 0.0688 & 7.50 & 36.63 \\
\hline 0.0814 & 8.72 & 45.36 \\
\hline 0.0964 & 9.74 & 55.09 \\
\hline 0.1141 & 10.28 & 65.37 \\
\hline 0.1350 & 10.09 & 75.46 \\
\hline 0.1598 & 8.99 & 84.45 \\
\hline 0.1811 & 7.05 & 91.05 \\
\hline 0.2042 & 4.68 & 96.18 \\
\hline 0.2255 & 2.50 & 98.68 \\
\hline 0.2534 & 1.00 & 99.68 \\
\hline 0.2911 & 0.27 & 99.95 \\
\hline 0.3393 & 0.05 & 100.00 \\
\hline 0.3904 & 0.00 & 100.00 \\
\hline 0.4257 & 0.00 & 100.00 \\
\hline
\end{tabular}

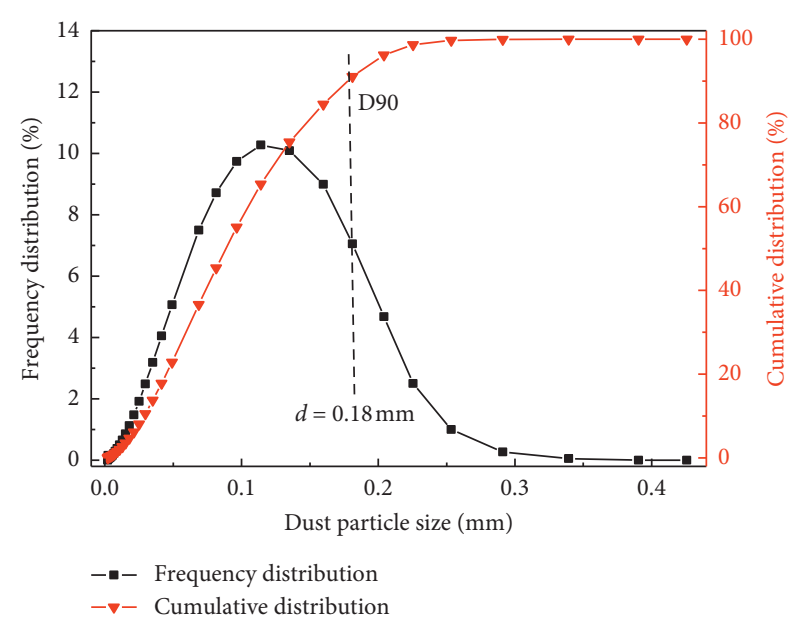

FIGURE 7: Dust particle size frequency and cumulative distribution.

From Figures 8 and 9, the distribution area of the particles in the furnace increases rapidly with time and fills almost the entire area within $2.0 \mathrm{~s}$. At $4.0 \mathrm{~s}$, the proportion of 

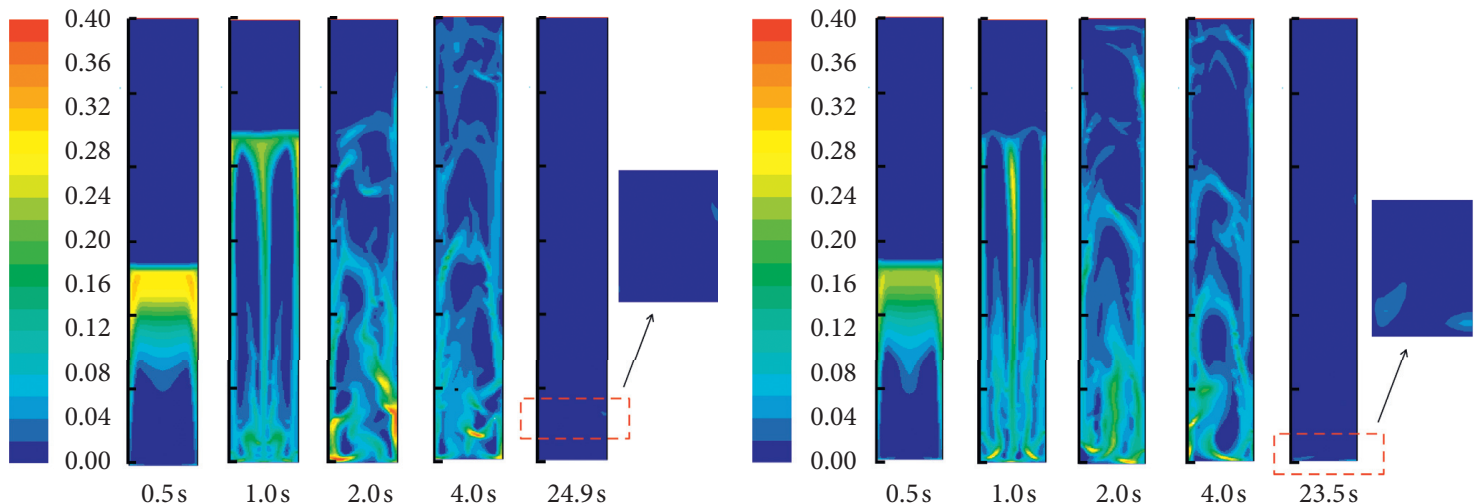

(a)
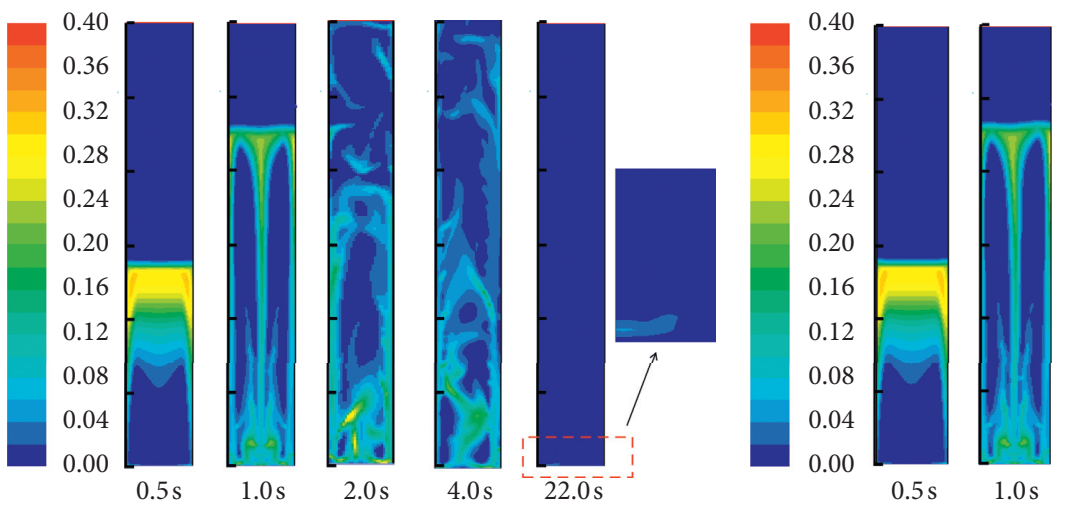

(b)

(c)
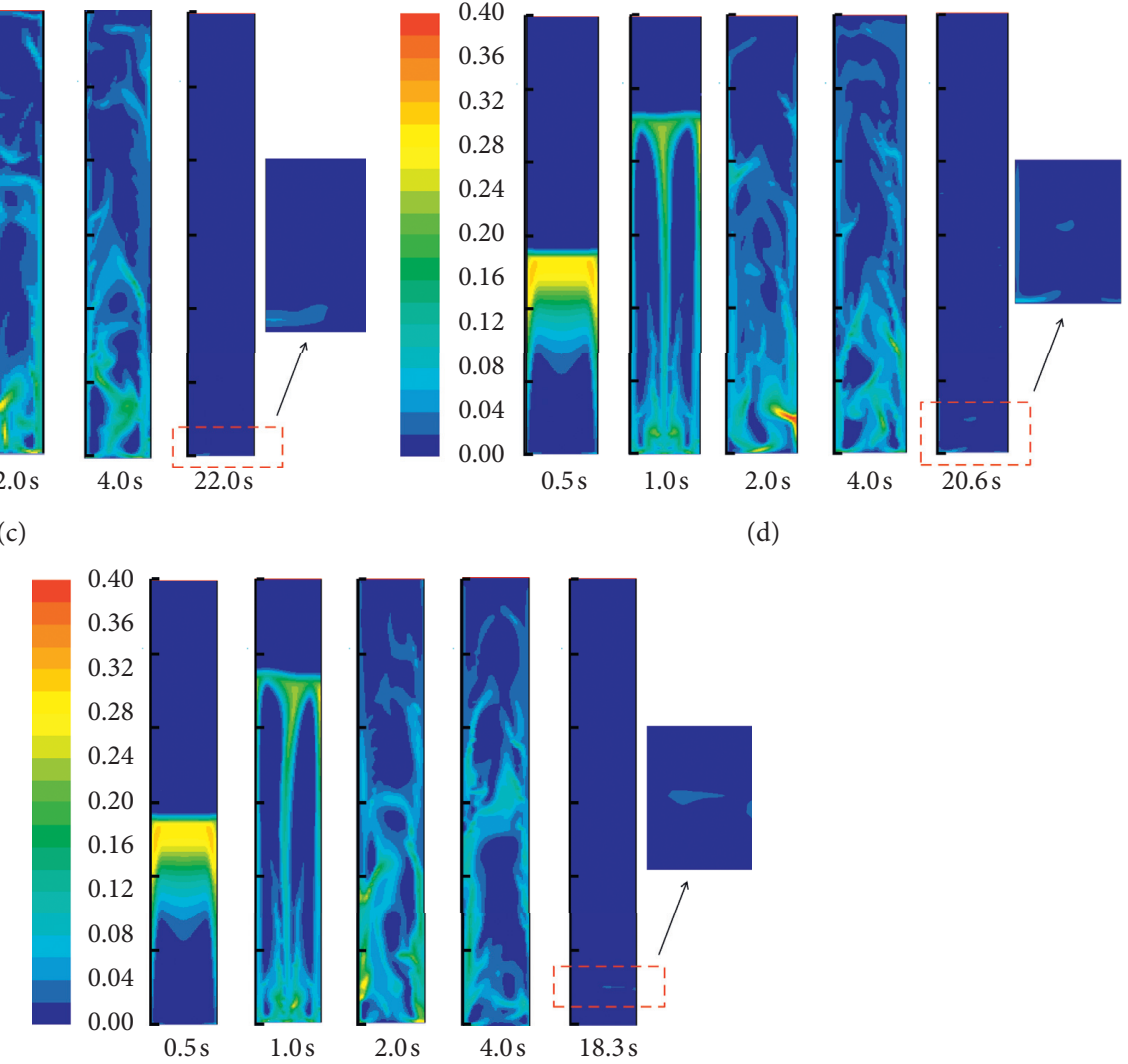

(d)

(e)

Figure 8: Volume fraction of tar mist: $d=0.20 \mathrm{~mm}$ and $\rho=900 \mathrm{~kg} / \mathrm{m}^{3}$. (a) $u=0.68 \mathrm{~m} / \mathrm{s}$. (b) $u=0.69 \mathrm{~m} / \mathrm{s}$. (c) $u=0.70 \mathrm{~m} / \mathrm{s}$. (d) $u=0.71 \mathrm{~m} / \mathrm{s}$. (e) $u=0.72 \mathrm{~m} / \mathrm{s}$.

particles (with a volume fraction of 0.20 to 0.40 ) continuously decreases, the particles gradually move upward, and the bottom is gradually occupied by a volume fraction of less than 0.12 . Finally, after approximately $20 \mathrm{~s}$ in the furnace, there is only a small amount of tar mist and dust particles with a volume fraction of 0.04 . The simulation results reveal that as the gas velocity increases, the time over which the tar mist and dust are completely removed gradually decreases. The reason is that the gravity $G$ of the mass per unit particle is constant in the case where the particle diameter and the density are the same. However, due to the difference in gas velocities, the resistance between the gas-solid phase and the additional force in the particle force balance may vary from equations (11)-(14). Following force balancing, an acceleration in the upward direction is finally obtained so that the time required for the belt to remove material decreases as the velocity increases.

A comparison of Figures 8 and 9 reveals that there is no change in the particle distribution shape, height, area, or volume fraction at $0.5 \mathrm{~s}$ and $1.0 \mathrm{~s}$. The reason may be that the increase in the velocity is not very large; the particle phase is initially at the bottom of the furnace, and the acceleration in the upward direction needs to gradually increase with time. After $2.0 \mathrm{~s}$, the acceleration starts to cause a visible change; 

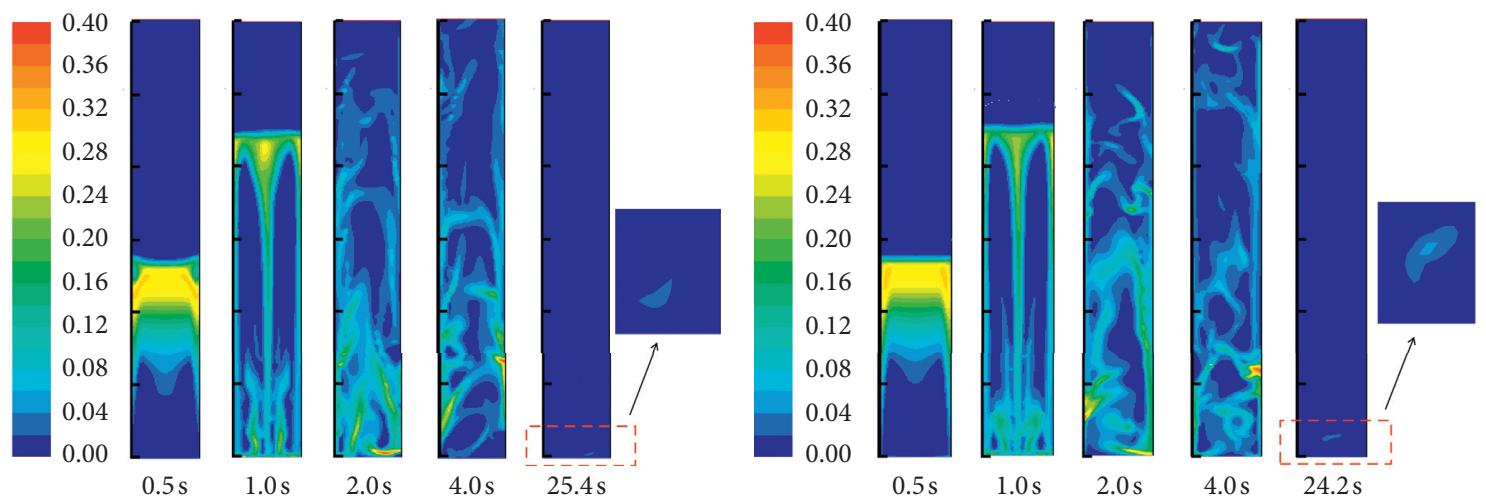

(a)
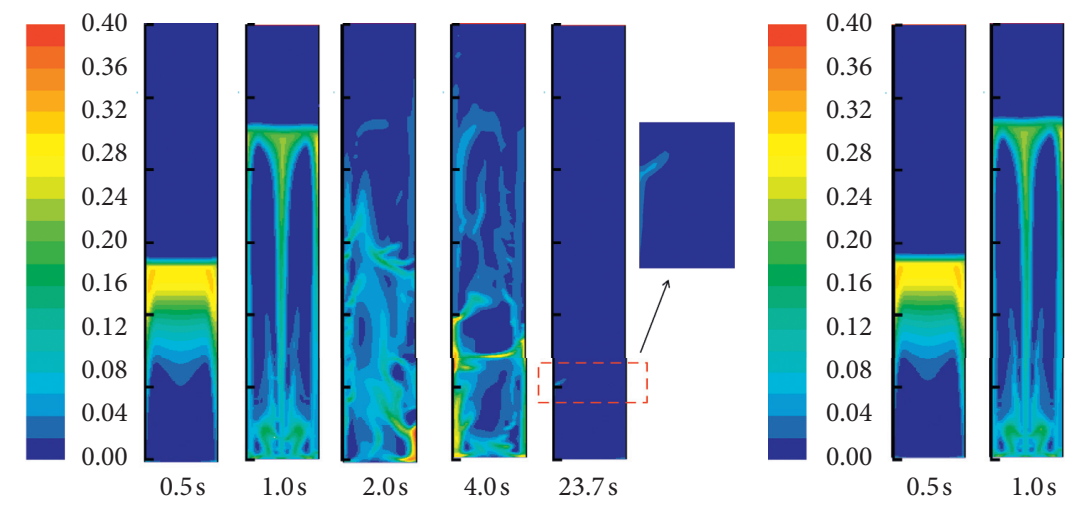

(b)

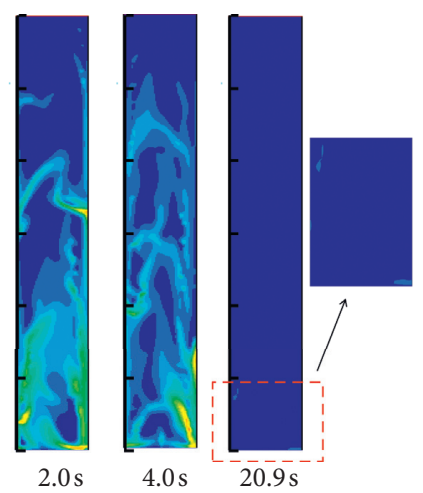

(c)

(d)
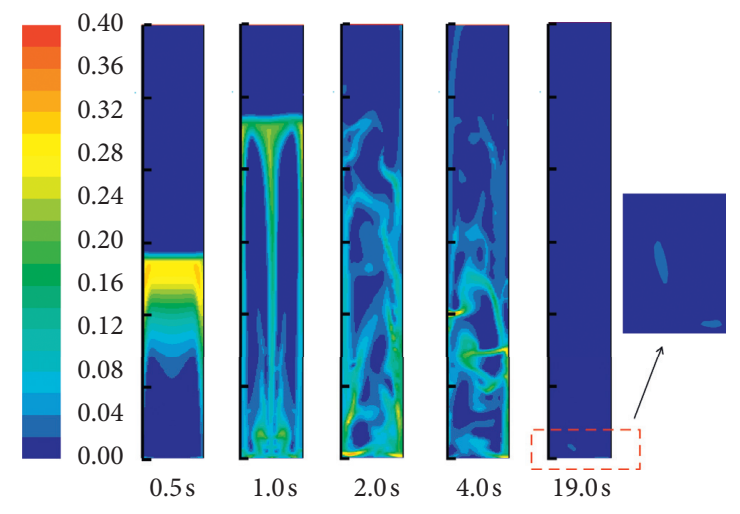

(e)

Figure 9: Volume fraction of dust: $d=0.18 \mathrm{~mm}$ and $\rho=1100 \mathrm{~kg} / \mathrm{m}^{3}$. (a) $u=0.68 \mathrm{~m} / \mathrm{s}$. (b) $u=0.69 \mathrm{~m} / \mathrm{s}$. (c) $u=0.70 \mathrm{~m} / \mathrm{s}$. (d) $u=0.71 \mathrm{~m} / \mathrm{s}$. (e) $u=0.72 \mathrm{~m} / \mathrm{s}$.

the volume fraction at the bottom decreases, the particles spread upward, and increasingly more particles are removed, gradually reducing the total time required for complete removal. Taken together with the simulation results at the same velocity, these results reveal that the time required for the dust to be removed is more than that for the tar mist to be removed. Because the difference in particle size is not very large, the difference in density plays a large role. Density determines the gravity force, and the density of tar mist is less than that of dust, meaning that the gravity force on the tar mist is less than that of dust of the same mass. At the same velocity, the other additional forces are unchanged, so the time required for the tar mist to be carried out is less than that for the dust.

Since the tar mist and dust are mixed into the furnace, the gas velocity is the same for both phases. The main purpose of this study was to separate the two phases, letting the tar mist be carried out and allowing as much dust as possible to flow back into the furnace for further dry distillation, so it is important to determine the appropriate corresponding velocity. Figure 10 presents the time at which the particles are removed in Figures 8 and 9. The time difference between 0.68 , $0.69,0.71$, and $0.72 \mathrm{~m} / \mathrm{s}$ is small, and all values lie within a range of $0.7 \mathrm{~s}$. At $0.70 \mathrm{~m} / \mathrm{s}$, the time difference is the largest, 


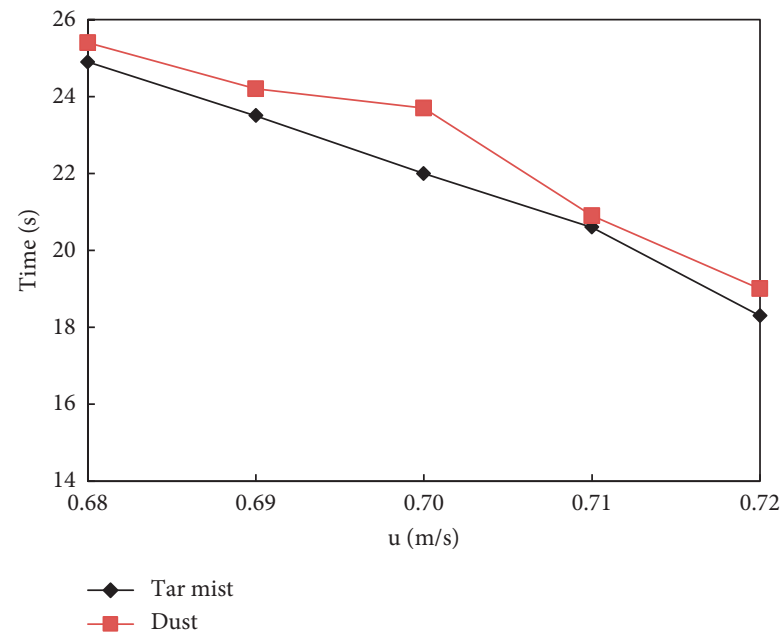

Figure 10: Particle removal time as a function of the gas velocity.
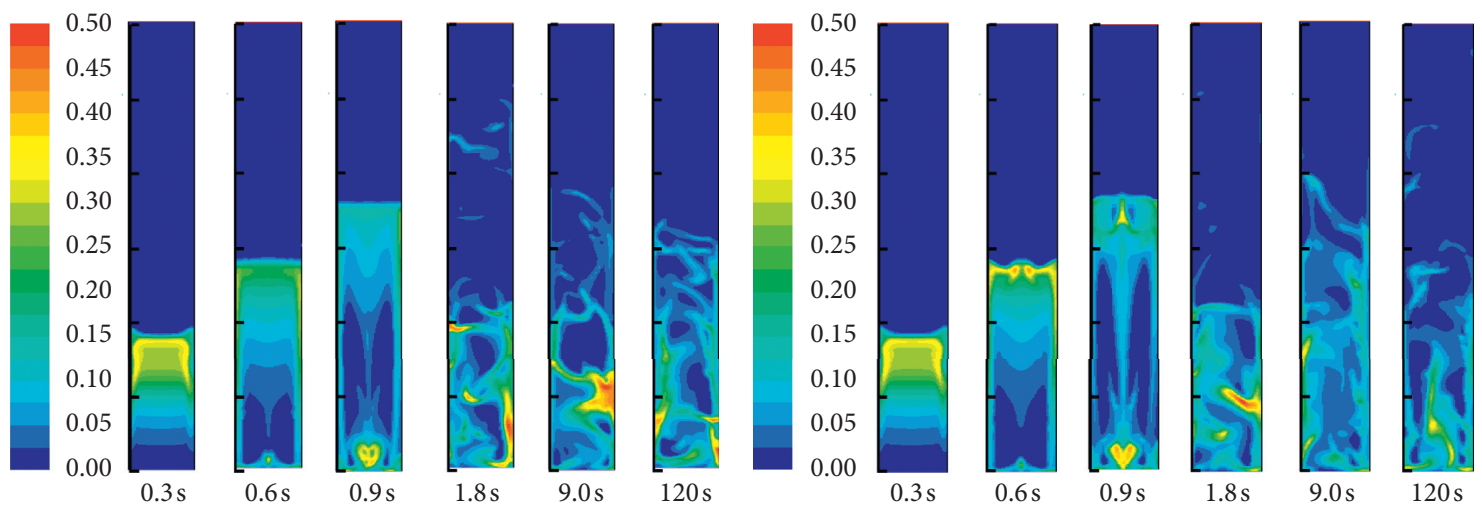

(a)

(b)

Figure 11: Volume fraction of tar mist: $d=0.30 \mathrm{~mm}$ and $\rho=900 \mathrm{~kg} / \mathrm{m}^{3}$. (a) $u=0.70 \mathrm{~m} / \mathrm{s}$. (b) $u=0.72 \mathrm{~m} / \mathrm{s}$.
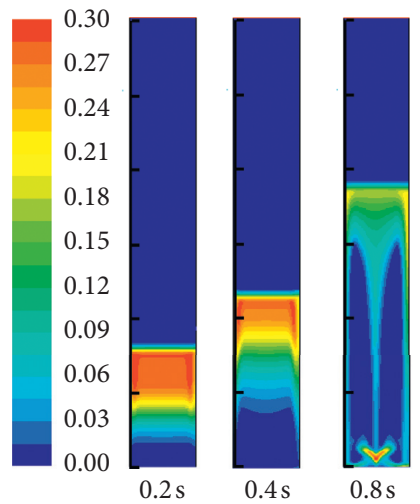

(a)
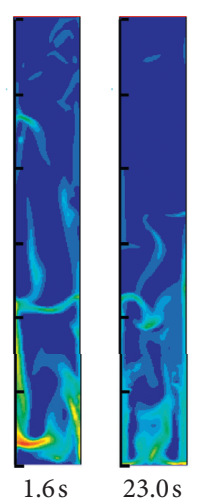

$23.0 \mathrm{~s}$

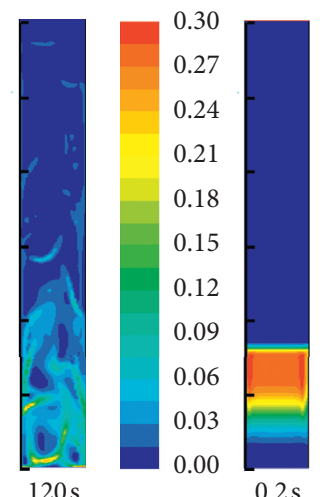

$0.2 \mathrm{~s}$

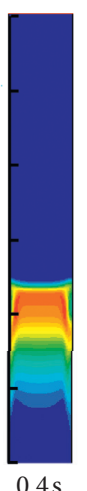

$0.4 \mathrm{~s}$

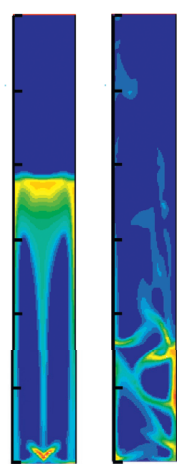

$0.8 \mathrm{~s} \quad 1.6 \mathrm{~s}$

(b)

FIgURE 12: Volume fraction of dust: $d=0.20 \mathrm{~mm}$ and $\rho=1100 \mathrm{~kg} / \mathrm{m}^{3}$. (a) $u=0.70 \mathrm{~m} / \mathrm{s}$. (b) $u=0.72 \mathrm{~m} / \mathrm{s}$.

which is $1.7 \mathrm{~s}$, which means that there is still more dust in the furnace when the tar mist is completely removed.

It can be seen from 5.1 and 5.2 that the above selected tar mist and dust particle size are the maximum values that can be removed by the gas. Select the two-phase particle with the smallest particle size when not removed and study the twophase motion at the maximum velocity, as shown in Figures 11 and 12. 

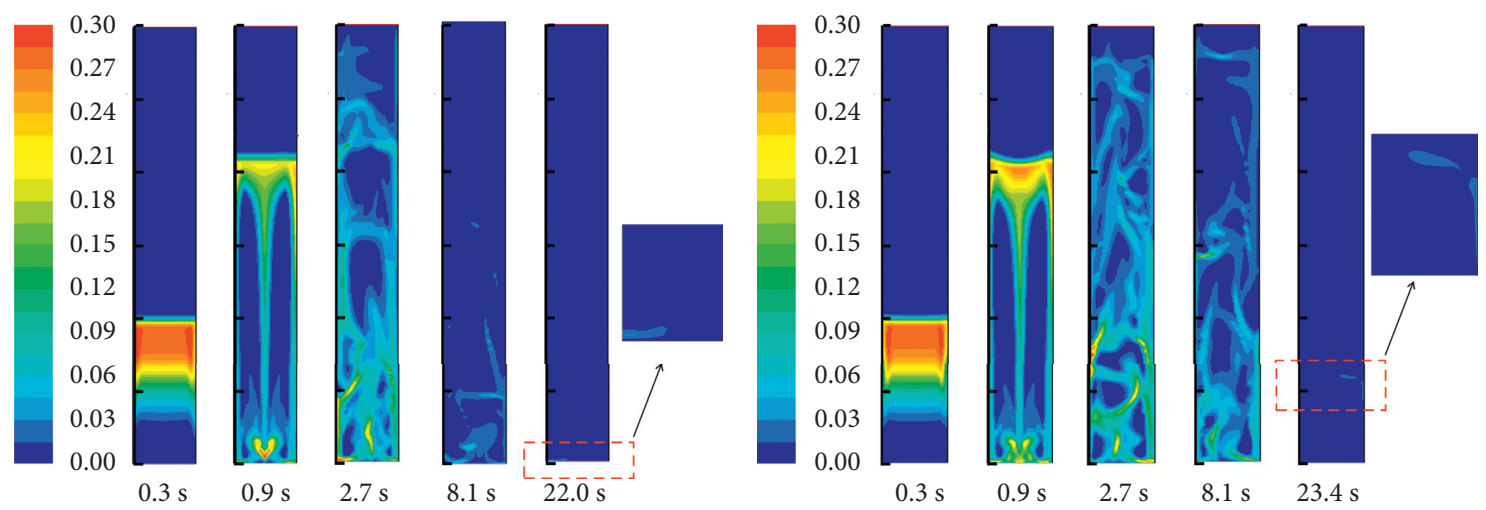

(a)
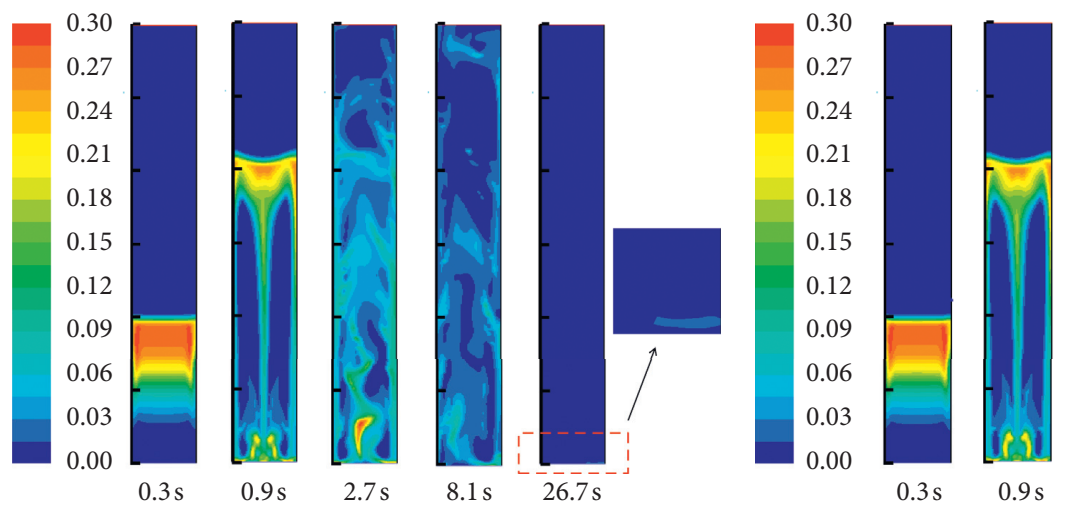

(b)

(c)
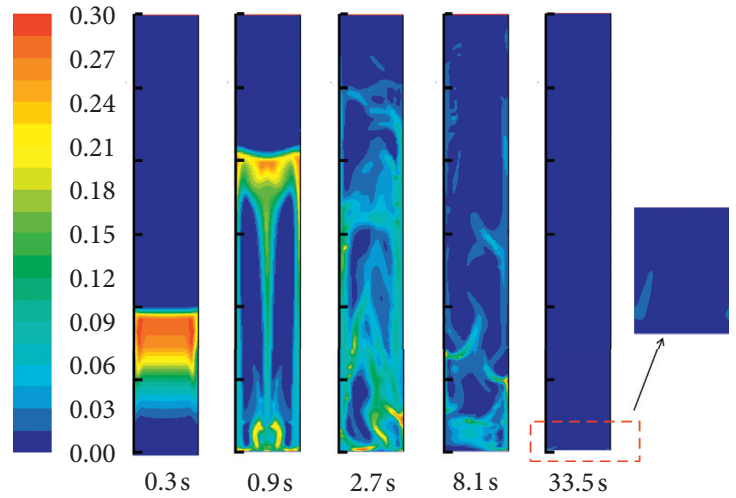

(d)

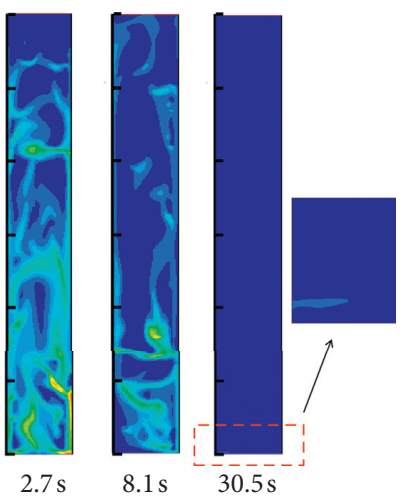

(e)

FIGURE 13: Volume fraction of tar mist: $d=0.20 \mathrm{~mm}$ and $u=0.70 \mathrm{~m} / \mathrm{s}$. (d) $\rho=1050 \mathrm{~kg} / \mathrm{m}^{3}$. (e) $\rho=1100 \mathrm{~kg} / \mathrm{m}^{3}$.

Figure 11 shows that the distribution area of particles in the furnace increases rapidly over time. At $1.8 \mathrm{~s}$, the particle fills the area to $5 / 6$, and the distribution area reaches its maximum. At $9.0 \mathrm{~s}$, the particle distribution area is reduced to $4 / 6$. At $120 \mathrm{~s}$, it is reduced to $1 / 2$, and the particles are always left in the furnace. A comparison of the simulation results at the same time reveals no change at $0.3 \mathrm{~s}$. With increasing velocity at $0.6 \mathrm{~s}$, the tar particles with a volume fraction of $0.35-0.45$ aggregate in a higher location, and the particles with a bottom volume fraction of $0.20-0.30$ are depleted. At $0.9 \mathrm{~s}$, as the velocity increases, tar particles are concentrated with a volume fraction of 0.30 to 0.40 and 0.35 to 0.45 at the upper and bottom portions of the distribution area, respectively. At $9.0 \mathrm{~s}$ and $120 \mathrm{~s}$, particles at a volume fraction of 0.35 to 0.50 disappear with increasing velocity, showing that although most of the particles remain in the furnace, some of them are still removed. It can be seen from Figure 12 that the distribution area of the particles in the furnace increases rapidly over time, and the entire area is filled in $1.6 \mathrm{~s}$, with the distribution of particles at a volume fraction of $0.18-0.30$ continuously decreasing in the working area. However, there are still some particles left in the furnace. A comparison of the simulation results at the same time reveals no change at $0.2 \mathrm{~s}$ and $0.4 \mathrm{~s}$; at $0.8 \mathrm{~s}$, particles 

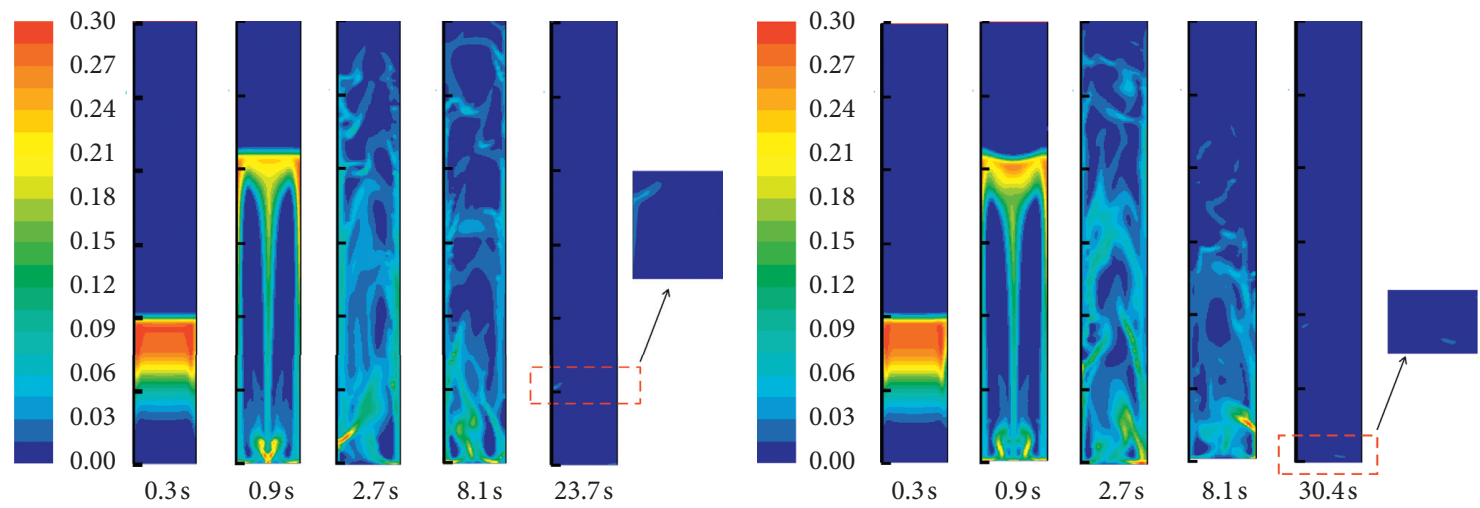

(a)
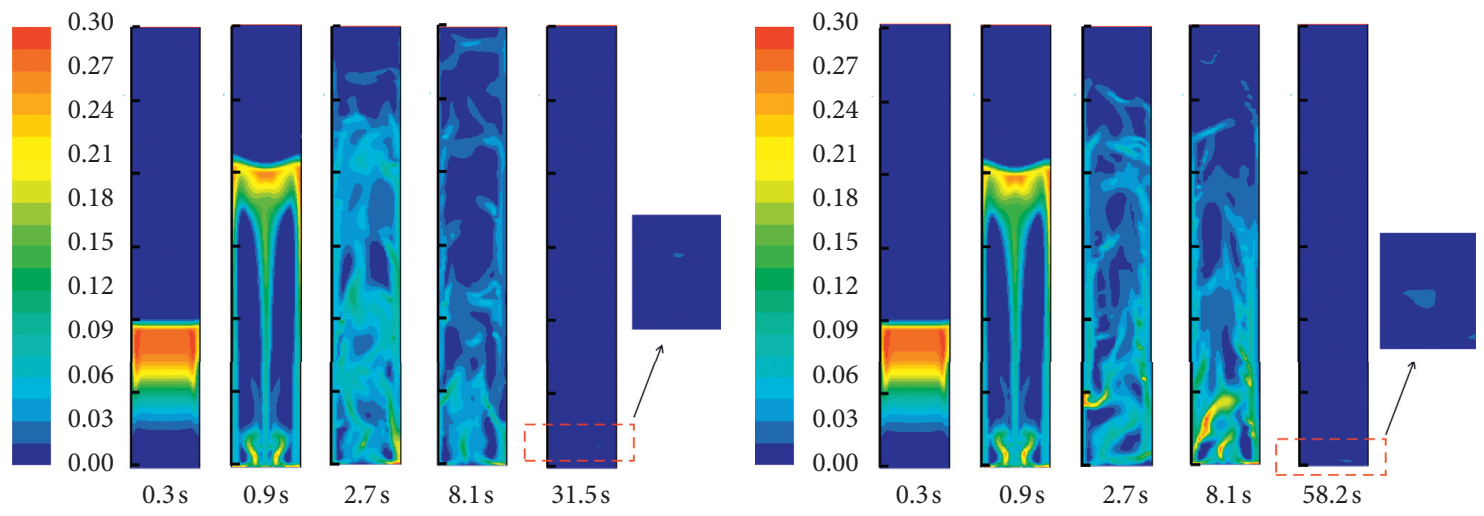

(c)

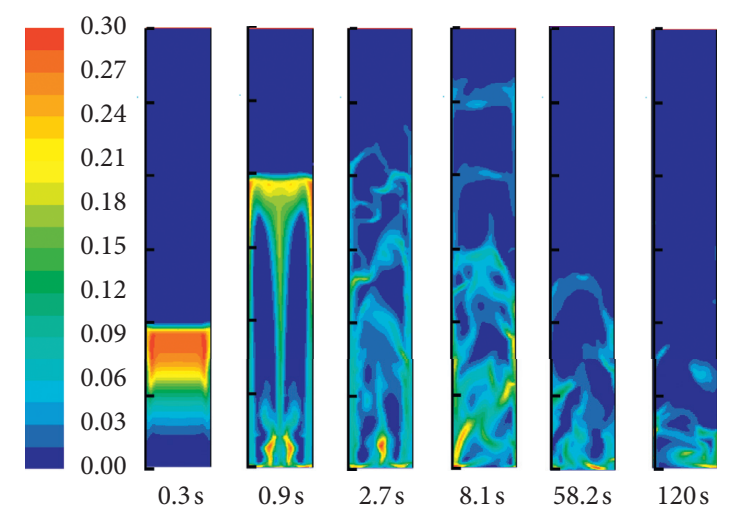

(d)

(e)

Figure 14: Volume fraction of dust: $d=0.18 \mathrm{~mm}$ and $u=0.70 \mathrm{~m} / \mathrm{s}$. (a) $\rho=1100 \mathrm{~kg} / \mathrm{m}^{3}$. (b) $\rho=1200 \mathrm{~kg} / \mathrm{m}^{3}$. (c) $\rho=1300 \mathrm{~kg} / \mathrm{m}^{3}$. $\rho=1400 \mathrm{~kg} / \mathrm{m}^{3}$. (e) $\rho=1500 \mathrm{~kg} / \mathrm{m}^{3}$.

(with a volume fraction of 0.21 to 0.27 ) are collected at a height of $4 / 6$, and there is no significant difference in the remaining time except that the distribution area is expanded from $1 / 2$ to $5 / 6$.

Figures $8,9,11$, and 12 verify that the gas velocity can change the length of time required for the two phases to be carried out, but the particle size of the particles is a key factor in determining whether removal is possible. The particle size of the tar mist should be less than $0.20 \mathrm{~mm}$, and the particle size of the dust should be greater than $0.18 \mathrm{~mm}$ to achieve the aims of this study.
5.5. Effect of the Tar Mist and Dust Density. The density of tar mist and dust was changed, and the two-phase motion was studied. The motion simulation results are shown in Figures 13 and 14.

Figure 13 shows that the distribution area of the particles in the furnace increases rapidly over time. At $2.7 \mathrm{~s}$, the particles fill almost the entire area, and the distribution of particles gradually decreases. Finally, at $33.5 \mathrm{~s}$, there is only a small amount of tar particles in the furnace, with a volume fraction of 0.03 . As the density increases, the time required to remove the particles increases because of the influence of 
gravity. There is little difference between the results at $0.3 \mathrm{~s}$ and $0.9 \mathrm{~s}$. The distribution area at $2.7 \mathrm{~s}$ is at a height of $5 / 6$; however, the particles (with a volume fraction of 0.06-0.12) are enriched with increasing density, and the particles are slowly transported to the bottom, with a volume fraction of 0.30 . At $8.1 \mathrm{~s}$, only particles at a volume fraction of 0.12 or less remain in the furnace. As the density increases, the distribution area first increases and then decreases. Specifically, only a few particles (with a volume fraction of 0.03 to 0.09 ) are left at $\rho=900 \mathrm{~kg} / \mathrm{m}^{3}$; at $\rho=950 \mathrm{~kg} / \mathrm{m}^{3}$ and $1000 \mathrm{~kg} / \mathrm{m}^{3}$, the density increases, and it is difficult to remove many particles at the same time, resulting in an increase in the distribution area. When $\rho=1050 \mathrm{~kg} / \mathrm{m}^{3}$ and $1100 \mathrm{~kg} / \mathrm{m}^{3}$, the volume fraction of the particles increases significantly, and the particles collectively move downward, resulting in a decrease in the distribution area. As shown in Figure 14, the distribution of particles in the furnace increases rapidly with time. The area is almost filled at $2.7 \mathrm{~s}$, and the distribution of particles in the area is then gradually reduced. The final density is between $1100 \mathrm{~kg} / \mathrm{m}^{3}$ and $1400 \mathrm{~kg} / \mathrm{m}^{3}$, and removal is difficult when the density is $1500 \mathrm{~kg} / \mathrm{m}^{3}$. A comparison of the simulation results indicates that since the density is less than that of the dust, the time required for tar mist removal is less than that of dust removal. The tar mist can be completely removed in the density range of $900-1100 \mathrm{~kg} / \mathrm{m}^{3}$. When the dust density is $1500 \mathrm{~kg} / \mathrm{m}^{3}$, the dust starts to gather at the bottom, and the degree of fluidization of the particles gradually decreases. At $120 \mathrm{~s}$, the particle fluidization degree is the lowest, and the dust is difficult to remove.

\section{Conclusions}

In this paper, a physical model of the two-phase motion of furnace gas, tar, and dust in the internal structure of the internal heat type low-temperature dry distillation furnace is established. The Euler-Lagrangian method is used to simulate the two-phase flow. The OMEC Topsizer Plus laser particle size analyzer is used to measure the particle size distribution of the dust to verify the accuracy of the mathematical model and the reliability of the simulation results. On this basis, the effects of gas velocity, tar particle size, and dust particle size on the movement of tar mist and dust are investigated. The following main conclusions are drawn:

(1) The tar particles with a particle diameter of less than $0.20 \mathrm{~mm}$ are removed from the furnace by the gas. The smaller the particle size, the shorter the time required for removal, the lower the probability of secondary pyrolysis of the tar, and the higher the tar recovery rate. In actual production, efforts should be made to reduce the particle size of the tar.

(2) Dust with a particle size greater than $0.18 \mathrm{~mm}$ cannot be removed from the furnace and remains in the furnace for pyrolysis, which not only increases the yield of the tar but also reduces the content of particulate impurities in the tar. In actual production, the coal powder generated by the breakage of coal in the furnace is reduced as much as possible.
(3) As the gas velocity increases, the time for the tar mist and dust to be completely removed gradually decreases. When the velocity is $0.70 \mathrm{~m} / \mathrm{s}$, the tar mist can be completely removed, but the dust with a particle diameter larger than $0.18 \mathrm{~mm}$ cannot be completely removed.

(4) Providing theoretical guidance for industrial production, the results indicate that the tar produced by low-temperature dry distillation can be quickly removed by the gas, while the dust such as pulverized coal and semicoke remains in the furnace. When the gas velocity is controlled to $0.70 \mathrm{~m} / \mathrm{s}$, the tar particle diameter at a density of $900 \mathrm{~kg} / \mathrm{m}^{3}$ is $0.10 \mathrm{~mm}$, and the particle size of the dust with a density of $1500 \mathrm{~kg} /$ $\mathrm{m}^{3}$ is $0.20 \mathrm{~mm}$.

\section{Data Availability}

The data used to support the findings of this study are available from the corresponding author upon request.

\section{Conflicts of Interest}

The authors declare that they have no conflicts of interest.

\section{Acknowledgments}

This work was supported by the National Natural Science Foundation of China (no. 21663034) and the Natural Science Foundation Program of Shaanxi Province for Joint fund project (no. 2019JLM-45).

\section{References}

[1] S. Peng, Bo Zhang, and T. Wang, "China's coal resources: octothorpe shaped distribution characteristics and sustainable development strategies," Engineering Sciences, vol. 17, no. 9, pp. 29-35, 2015.

[2] Y. Zhu and Z. Wang, Coal Chemistry, Chemical Industry Press, Beijing, China, 2013.

[3] Z. Liu, H. Chen, and W. Huang, "The current situation of coal resources \& prospecting straegy in China," Coal Technology, vol. 24, no. 10, pp. 1-2, 2005.

[4] Y. Wang, D. Guo, H. Zhang et al., "Spatial distribution of coal resource potential in China and its application," Journal of Natural Resources, vol. 21, no. 2, pp. 225-230, 2006.

[5] K. Xie, Research on the Development Strategy of Energy, Chemical Industry Press, Golden Triangle, Thailand, 2016.

[6] T. Yao, Li Wang, H. Jingtuan et al., "Study on coal liquefied technology," Guangzhou Chemical Industry, vol. 42, no. 15, pp. 34-35, 2014.

[7] J. Chen and X. Hong, "Coal gasification technology," Chemical Engineering \& Equipment, vol. 4, no. 4, pp. 110-111, 2011.

[8] Y. Sun, "Analysis of the development status and trend of coal chemical technology," China Petroch2em, vol. 23, no. 23, pp. 115-116, 2016.

[9] T. Bai, "Coal low-temperature pyrolysis multi-generation technology-the best way to achieve clean and efficient use of coal," Coal Processing \& Comprehensive Utilization, vol. 1, no. 12, pp. 6-10, 2014. 
[10] L. Hao, W. Song, X. Zhang et al., "Application and development of pyrolysis technology in low-carbon economy," Journal of Engineering Studies, vol. 4, no. 3, pp. 231-236, 2012.

[11] Y. Wang, Y. Wang, Y. Dong et al., "Development prospect of semi-coke coal tar and dry distillation gas produced by coal dry distillation," Petrochemical Industry Application, vol. 27, no. 6, pp. 1-3, 2008.

[12] K. Cen, M. Ni, Z. Luo et al., "The prospect of power generation technology based on coal staged conversion," Engineering Sciences, vol. 17, no. 9, pp. 118-122, 2015.

[13] Y. He, "Economic analysis of coal pyrolysis and tar processing technology," Energy and Transportation, vol. 18, no. 18, pp. 24-25, 2010.

[14] Y. Song and J. Tang, Coal Chemical Technology, Chemical Industry Press, Beijing, China, 2016.

[15] G.-Q. Chen and Z.-H. Luo, "New insights into intraparticle transfer, particle kinetics, and gas-solid two-phase flow in polydisperse fluid catalytic cracking riser reactors under reaction conditions using multi-scale modeling," Chemical Engineering Science, vol. 109, pp. 38-52, 2014.

[16] J. Gao, C. Xu, S. Lin, G. Yang, and Y. Guo, "Simulations of gasliquid-solid 3-phase flow and reaction in FCC riser reactors," AIChE Journal, vol. 47, no. 3, pp. 677-692, 2001.

[17] C. Wu, Y. Cheng, and Y. Jin, "Understanding riser and downer based fluid catalytic cracking processes by a comprehensive two-dimensional reactor model," Industrial \& Engineering Chemistry Research, vol. 48, no. 1, pp. 12-26, 2009.

[18] Y. Wu, Q. Zhang, W. Yang, and W. Blasiak, "Two-dimensional computational fluid dynamics simulation of biomass gasification in a downdraft fixed-bed gasifier with highly preheated air and steam," Energy \& Fuels, vol. 27, no. 6, pp. 3274-3282, 2013.

[19] H. R. Nazif and H. Basirat Tabrizi, "Development of boundary transfer method in simulation of gas-solid turbulent flow of a riser," Applied Mathematical Modelling, vol. 37, no. 4, pp. 2445-2459, 2013.

[20] S. Akhshik, M. Behzad, and M. Rajabi, "CFD-DEM approach to investigate the effect of drill pipe rotation on cuttings transport behavior," Journal of Petroleum Science and Engineering, vol. 127, pp. 229-244, 2015.

[21] F. Chaumeil and M. Crapper, "Using the DEM-CFD method to predict Brownian particle deposition in a constricted tube," Particuology, vol. 15, pp. 94-106, 2014.

[22] I. Goldasteh, G. Ahmadi, and A. R. Ferro, "Monte Carlo simulation of micron size spherical particle removal and resuspension from substrate under fluid flows," Journal of Aerosol Science, vol. 66, pp. 62-71, 2013.

[23] J. Toraño, S. Torno, M. Menéndez, and M. Gent, "Auxiliary ventilation in mining roadways driven with roadheaders: validated CFD modelling of dust behaviour," Tunnelling and Underground Space Technology, vol. 26, no. 1, pp. 201-210, 2011.

[24] J. C. Kurnia, A. P. Sasmito, A. S. Mujumdar, and S. Arun, "Dust dispersion and management in underground mining faces," International Journal of Mining Science and Technology, vol. 24, no. 1, pp. 39-44, 2014.

[25] N. A. Patankar and D. D. Joseph, "Modeling and numerical simulation of particulate flows by the Eulerian-Lagrangian approach," International Journal of Multiphase Flow, vol. 27, no. 10, pp. 1659-1684, 2001.

[26] Y. Lu, A. Saad, A. P. Sasmito, and J. C. Kurnia, "Prediction of air flow, methane, and coal dust dispersion in a room and pillar mining face," International Journal of Mining Science and Technology, vol. 27, pp. 657-662, 2017.

[27] G. Zhou, Q. Zhang, R. Bai, T. Fan, and G. Wang, "The diffusion behavior law of respirable dust at fully mechanized caving face in coal mine: CFD numerical simulation and engineering application," Process Safety and Environmental Protection, vol. 106, pp. 117-128, 2017.

[28] P. Cai, W. Nie, D. Chen, S. Yang, and Z. Liu, "Effect of air flowrate on pollutant dispersion pattern of coal dust particles at fully mechanized mining face based on numerical simulation," Fuel, vol. 239, pp. 623-635, 2019.

[29] G. Sankar, D. S. Kumar, and K. R. Balasubramanian, "Computational modeling of pulverized coal fired boilers-a review on the current position," Fuel, vol. 236, pp. 643-665, 2019.

[30] G. Zhou, B. Feng, W. Yin, and J. Wang, "Numerical simulations on airflow-dust diffusion rules with the use of coal cutter dust removal fans and related engineering applications in a fully-mechanized coal mining face," Powder Technology, vol. 339, pp. 354-367, 2018.

[31] B. Taraba, Z. Michalec, V. Michalcová, T. Blejchař, M. Bojko, and M. Kozubková, "CFD simulations of the effect of wind on the spontaneous heating of coal stockpiles," Fuel, vol. 118, pp. 107-112, 2014.

[32] R. Zhou, N. Yang, and J. Li, "CFD simulation of gas-liquidsolid flow in slurry bubble columns with EMMS drag model," Powder Technology, vol. 314, pp. 466-479, 2017.

[33] J. C. Kurnia, A. P. Sasmito, and A. S. Mujumdar, "CFD simulation of methane dispersion and innovative methane management in underground mining faces," Applied Mathematical Modelling, vol. 38, no. 14, pp. 3467-3484, 2014.

[34] J. Cheng, S. Li, F. Zhang, C. Zhao, S. Yang, and A. Ghosh, "CFD modelling of ventilation optimization for improving mine safety in longwall working faces," Journal of Loss Prevention in the Process Industries, vol. 40, pp. 285-297, 2016.

[35] A. M. Eaton, L. D. Smoot, S. C. Hill, and C. N. Eatough, "Components, formulations, solutions, evaluation, and application of comprehensive combustion models," Progress in Energy and Combustion Science, vol. 25, no. 4, pp. 387-436, 1999.

[36] W. Li, S. Lu, Y. Liu, R. Wang, Q. Huang, and J. Yan, "CFD simulation of the unsteady flow of a single coal log in a pipe," The Canadian Journal of Chemical Engineering, vol. 93, no. 11, pp. 2084-2093, 2015.

[37] M. K. Neuman, J. W. Boulton, and S. Sanderson, "Wind tunnel simulation of environmental controls on fugitive dust emissions from mine tailings," Atmospheric Environment, vol. 43 , pp. 520-529, 2009.

[38] Z. Jiang, L. Jiang, and J. Chen, "Numerical simulation of dust concentration distribution regularities of down-the-hole drilling in open-pit mine," Journal of Shenzhen University Science and Engineering, vol. 30, no. 3, pp. 313-318, 2013.

[39] M. W. Korevaar, J. T. Padding, M. A. V. D. Hoef, and J. A. M. Kuipers, "Integrated DEM-CFD modeling of the contact charging of pneumatically conveyed powders," Powder Technology, vol. 258, pp. 144-156, 2014.

[40] G. Zhou, W. Cheng, L. Chen, and W. Nie, "Numerical simulation and its application of dust concentration spatial distribution regularities in fully-mechanized caving face," Journal of China Coal Society, vol. 35, pp. 2094-2099, 2010.

[41] A. Milićević, S. Belošević, N. Crnomarković et al., "Mathematical modelling and optimisation of lignite and wheat straw cocombustion in $350 \mathrm{MW}_{\mathrm{e}}$ boiler furnace," Applied Energy, vol. 260, p. 114206, 2020. 
[42] Q. Zhang, G. Zhou, X. Qian, M. Yuan, Y. Sun, and D. Wang, "Diffuse pollution characteristics of respirable dust in fullymechanized mining face under various velocities based on CFD investigation," Journal of Cleaner Production, vol. 184, pp. 239-250, 2018.

[43] A. Li and G. Ahmadi, "Dispersion and deposition of spherical particles from point sources in a turbulent channel flow," Aerosol Science and Technology, vol. 16, no. 4, pp. 209-226, 1992.

[44] P. G. Saffman, "The lift on a small sphere in a slow shear flow," Journal of Fluid Mechanics, vol. 22, no. 2, pp. 385-400, 1965. 